CLINICAL STUDY

\title{
Relationship between lactation duration and insulin and glucose response among women with prior gestational diabetes
}

\author{
Sarah Chouinard-Castonguay ${ }^{1,2}$, S John Weisnagel $^{3,4}$, André Tchernof ${ }^{1,2,4}$ and Julie Robitaille ${ }^{1,2}$ \\ ${ }^{1}$ Department of Food Science and Nutrition, Laval University, Quebec City, Quebec, Canada, ${ }^{2}$ Institute of Nutraceuticals and Functional Food (INAF), \\ Laval University, 2440 Hochelaga Boulevard, Room 2729-N, Quebec City, Quebec, Canada G1V OA6, ${ }^{3}$ Diabetes Research Unit, Laval University \\ Medical Research Center, Quebec City, Quebec, Canada and ${ }^{4}$ Endocrinology and Nephrology, Laval University Medical Research Center, Quebec City, \\ Quebec, Canada
}

(Correspondence should be addressed to J Robitaille; Email: julie.robitaille@fsaa.ulaval.ca)

\begin{abstract}
Background: Few studies have investigated whether favorable effects of lactation persist after weaning and protect women with prior gestational diabetes mellitus (GDM) against later development of insulin resistance and insulin secretion defects.

Objective: To investigate the impact of lactation duration on insulin and glucose response among women with prior GDM.

Design/methods: The study group comprised 144 women with a history of GDM between 2003 and 2010. Plasma insulin and glucose concentrations were obtained from a $75 \mathrm{~g}$ oral glucose tolerance test (OGTT). Total lactation duration (exclusive breastfeeding and breast and bottle-feeding) for all infants was self-reported in months.

Results: Mean age was 36.5 \pm 5.0 years. Time between delivery and metabolic testing was $4.0 \pm 1.9$ years. Women breastfed for an average of $13.9 \pm 16.8$ months. Most women $(80.6 \%)$ reported a history of lactation. Women who lactated had higher homeostasis model assessment for insulin sensitivity (HOMA-IS) and Matsuda indices and lower fasting and 2-h post-OGTT insulin concentrations as well as area under the curve (AUC) for insulin $(P \leq 0.01$ for all). Compared with women who lactated for $<10$ months, women who lactated for $\geq 10$ months had improved insulin sensitivity-secretion index, higher HOMA-IS and Matsuda indices, lower fasting and 2-h post-OGTT insulin concentrations as well as AUC for insulin, and lower incidence of impaired glucose intolerance $(P \leq 0.05$ for all). In multiple linear regression analyses, lactation duration emerged as an independent predictor of fasting insulin concentrations $(\beta=-0.02)$ and insulin sensitivity indices $(\beta=0.02)$ $(P \leq 0.05$ for all $)$.

Conclusions: These results suggest that longer duration of lactation is associated with improved insulin and glucose response among women with prior GDM.
\end{abstract}

European Journal of Endocrinology 168 515-523

\section{Introduction}

Gestational diabetes mellitus (GDM) is defined as the onset or first recognition of glucose intolerance during pregnancy (1). During pregnancy, women with GDM display metabolic abnormalities similar to those of people with type 2 diabetes (T2D), such as insulin resistance and reduced pancreatic $\beta$-cell compensation for that resistance (2). GDM most often resolves at delivery but insulin resistance and insulin secretion defects remain common in the post partum period $(3,4,5)$.

Lactation is encouraged for women with prior GDM because it may confer health benefits to women with a history of GDM $(6,7,8)$ and has been suggested to be associated with increased insulin sensitivity (9), improved insulin secretion (10), and improved glucose tolerance $(6,11)$. A study by Gunderson et al. (9) showed that lactation may exert favorable effects on insulin sensitivity. However, in another study, 3 months of lactation in a population with previous GDM was not associated with fasting glucose or insulin values, but improved insulin sensitivity was associated with improved $\beta$-cell function (10), suggesting that other studies are needed to better understand beneficial effects of lactation among women with prior GDM.

Because only few studies have investigated whether favorable effects of lactation persist after weaning and protect women with prior GDM against later development of insulin and glucose response defects, the aim of this study was to investigate the impact of lactation duration on insulin and glucose response among women with prior GDM. We hypothesized that longer 
duration of lactation is associated with improved insulin concentrations, sensitivity, and secretion as well as improved glucose concentrations and tolerance among women with prior GDM.

\section{Materials and methods}

\section{Study population}

The study population has been described previously (12). Briefly, a total of 215 eligible women from the greater Quebec region (Capitale-Nationale and ChaudièresAppalaches) with a history of GDM between 2003 and 2010 were invited to come to the clinical investigation unit of the Institute of Nutraceuticals and Functional Foods (INAF) of Laval University, Quebec City, between October 2009 and August 2011. Women who had a bariatric surgery $(n=1)$ or multiple pregnancy $(n=2)$, who were exclusively breastfeeding at the time of the study $(n=2)$, who used T2D medication $(n=7)$ and with missing data for variables considered in the analyses (lactation duration, insulin profile, or current physical activity $(n=59))$ because of incomplete questionnaires were excluded, leaving a total of 144 women in the final analyses. Excluded women were not different from the study group $(P>0.05)$. All subjects provided written consent to participate in this study, which has been approved by the Ethics Committee of Laval University.

\section{Oral glucose tolerance test}

A $75 \mathrm{~g} \mathrm{2-h}$ oral glucose tolerance test (OGTT) was performed in the morning after an overnight fast. Blood samples were collected at $-15,0,15,30,60,90$, and $120 \mathrm{~min}$ for the measurement of plasma glucose and insulin concentrations. Plasma glucose was measured enzymatically (13) whereas plasma insulin was measured by RIA (14). Impaired fasting glucose was characterized by a fasting glucose value between 6.1 and $6.9 \mathrm{mmol} / \mathrm{l}$ and impaired glucose tolerance by a normal fasting glucose value $(<6.1 \mathrm{mmol} / \mathrm{l})$ and 2 -h post-OGTT glucose value between 7.8 and $11.0 \mathrm{mmol} / \mathrm{l}$ (women with T2D were excluded). The homeostasis model assessment for insulin sensitivity (HOMA-IS) index calculated as $1 /(($ fasting insulin concentration $\times$ fasting glucose concentration)/22.5) (15) and the Matsuda index calculated as $10000 / \sqrt{ }$ (fasting glucose concentration $\times$ fasting insulin concentration $\times($ mean glucose $\times$ mean insulin)) (16) were obtained. Insulin secretion was estimated by the ratio of the area under the curve (AUC) for insulin to the AUC for glucose. Insulin sensitivity-secretion index (ISSI) was calculated as the product of insulin secretion and insulin sensitivity calculated using the Matsuda index $(17,18)$. This OGTT-derived measure has been shown to be correlated with the disposition index obtained from frequently sampled intravenous glucose tolerance test $(18,19)$. In addition, we calculated the insulinogenic index for insulin secretion (insulin $30 \mathrm{~min}-$ fasting insulin/glucose $30 \mathrm{~min}$ - fasting glucose) (20).

\section{Data collection}

Body weight and height were measured and BMI was calculated $\left(\mathrm{kg} / \mathrm{m}^{2}\right)$. Weight prior to any pregnancy was self-reported by women and was used to calculate BMI prior to any pregnancy. Lactation duration for each pregnancy was retrospectively self-reported in months by the participants. Questionnaires were filled by each participating woman during their visit at the clinical investigation unit. Total duration of lactation was defined as the sum of the months of lactation, either exclusive breastfeeding or breast and bottle-feeding, for all of the participant's infants. Nutritional information was obtained from a validated food frequency questionnaire (FFQ) (21). The FFQ was designed to assess food intake over the last month. Daily usual dietary intakes were obtained. This questionnaire has been validated in a sample of the population of the greater Quebec area and is reproducible (21). Nutrient analyses of the FFQ were performed using the Nutrition Data System for Research (NDS-R) version 4.03, developed by the Nutrition Coordinating Center, University of Minnesota, Minneapolis, MN. To report physical activity, women completed the International Physical Activity Questionnaire (IPAQ). Total physical activity of moderate and high intensity was obtained (22). Insulin use during at least one pregnancy as well as parity and education level were self-reported by the participants. Time since last GDM-complicated pregnancy delivery was calculated from the difference between the delivery date of the GDM-complicated pregnancy based on the RAMQ data and the day of metabolic testing.

\section{Statistical analysis}

Variables were tested for normality of distribution and non-normally distributed variables were log or square root transformed. ANOVAs were performed to examine the association between women who lactated or not and insulin concentrations, indices of insulin sensitivity and insulin secretion, as well as glucose concentrations and glucose tolerance. The associations between duration of lactation in months (stratified in two groups using the median of 10 months) and insulin and glucose response measures were assessed using ANOVAs. Analyses were then adjusted for age, current energy intake, current physical activity, current BMI, insulin use during pregnancy, education level, parity, and time since last GDM-complicated pregnancy delivery. These variables were selected based on associations with the studied outcomes in the current study or based on their presumed physiological role. Differences between characteristics of the lactation groups were calculated 
by ANOVA for continuous variables and by $\chi^{2}$ test for categorical variables. Multiple linear regression analyses were performed to identify independent predictors of glucose and insulin concentrations and indices of insulin sensitivity and insulin secretion. The models included lactation duration in months, age, current energy intake, current physical activity, current BMI, insulin use during pregnancy, education level, parity, and time since last GDM-complicated pregnancy delivery. All statistical analyses were performed using SAS statistical software, version 9.2 (SAS Institute, Inc., Cary, NC, USA), and $P \leq 0.05$ was used to identify a statistically significant result.

\section{Results}

Characteristics of the participants are given in Table 1. Mean age was $36.5 \pm 5.0$ years. Mean BMI was $27.5 \pm 6.5 \mathrm{~kg} / \mathrm{m}^{2}$. Participants were enrolled in the study $4.0 \pm 1.9$ (range from 1 to 7 years) years after

Table 1 Characteristics of the participants $(n=144)$. Results are presented as mean \pm s.D.

\begin{tabular}{|c|c|c|}
\hline Characteristics & $n(\%)$ & Mean \pm S.D. \\
\hline Age (years) & & $36.5 \pm 5.0$ \\
\hline Parity & & $2.1 \pm 0.8$ \\
\hline Energy intake (kcal) & & $227 \overline{5} \pm 646$ \\
\hline Physical activity (min/week) & & $99.8 \pm 42.5$ \\
\hline Insulin use, yes & $79(54.9)$ & - \\
\hline $\begin{array}{l}\text { Time since last GDM-complicated } \\
\text { pregnancy delivery (years) }\end{array}$ & & $\begin{array}{l}4.0 \pm 1.9 \\
\quad \text { (range: } 1-7)\end{array}$ \\
\hline BMI $\left(\mathrm{kg} / \mathrm{m}^{2}\right)$ & & $27.5 \pm 6.5$ \\
\hline \multicolumn{3}{|l|}{ Education } \\
\hline Secondary & $30(21.0)$ & - \\
\hline Post secondary & $113(79.0)$ & - \\
\hline \multicolumn{3}{|l|}{ Household income $(\$)$} \\
\hline 0-39 999 & $23(17.2)$ & - \\
\hline $40000-79999$ & $48(35.8)$ & - \\
\hline $80000+$ & $63(47.0)$ & - \\
\hline Fasting glucose $(\mathrm{mmol} / \mathrm{l})$ & & $5.8 \pm 0.7$ \\
\hline 2-h post-OGTT glucose $(\mathrm{mmol} / \mathrm{l})$ & & $8.2 \pm 2.3$ \\
\hline \multicolumn{3}{|l|}{ Impaired fasting glucose } \\
\hline Yes & $31(25.2)$ & - \\
\hline No & $92(74.8)$ & - \\
\hline \multicolumn{3}{|l|}{ Impaired glucose tolerance } \\
\hline Yes & $39(31.7)$ & - \\
\hline No & $84(68.3)$ & _- \\
\hline Fasting insulin (pmol/l) & & $87.2 \pm 46.2$ \\
\hline 2-h post-OGTT insulin (pmol/l) & & $661 \pm 431$ \\
\hline AUC for insulin (pmol/l per min) & & $630 \overline{7} 9 \pm 32942$ \\
\hline HOMA-IS index & & $0.060 \pm 0.041$ \\
\hline Matsuda index & & $10.3 \pm 5.6$ \\
\hline Insulin secretion & & $61.0 \pm 2.5$ \\
\hline Insulinogenic index & & $136 \pm 9$ \\
\hline ISSI & & $535 \pm 203$ \\
\hline Type 2 diabetes, yes & $21(14.6)$ & - \\
\hline Lactation duration (months) & & $13.8 \pm 16.8$ \\
\hline Yes & $116(80.6)$ & - \\
\hline No & $28(19.4)$ & - \\
\hline
\end{tabular}

OGTT, $75 \mathrm{~g}$ 2-h oral glucose tolerance test; AUC, area under the curve; HOMA-IS, homeostasis model assessment for insulin sensitivity; ISSI, insulin sensitivity-secretion index. the last GDM-complicated pregnancy delivery date. Total duration of lactation was $13.9 \pm 16.8$ months. Most women $(80.6 \%)$ reported a history of lactation. There was no difference between women who lactated and women who did not except that women in the lactation group were older and had higher education level compared with women who did not lactate $(P<0.05$ for both, Table 2$)$. Characteristics of the participants were also similar between women who lactated for a total $<10$ and for a total $\geq 10$ months $(P>0.05$, Table 3$)$.

No difference was observed for glucose concentrations, impaired fasting glucose, or impaired glucose tolerance between women who lactated or not $(P>0.05$ for all, Table 2). Women who lactated had lower fasting and 2-h post-OGTT insulin concentrations and AUC for insulin $(P \leq 0.01$ for all, Table 2$)$. Women in the lactation group were also characterized by higher HOMA-IS and Matsuda indices $(P \leq 0.01$ for both, Table 2). Women who lactated had a lower insulin secretion calculated by the AUC ratio $(P=0.03$, Table 2$)$ but not according to the insulinogenic index $(P>0.05$, Table 2). There was no difference in ISSI index between the lactation and the non-lactation groups $(P>0.05$, Table 2). Results were similar after adjustments for age, current energy intake, current physical activity, current BMI, insulin use during pregnancy, education level, parity, and time since last GDM-complicated pregnancy delivery.

There was no difference for glucose concentrations and for the proportion of women with impaired fasting glucose between women who lactated for a total $<10$ and for a total $\geq 10$ months ( $P>0.05$ for all, Table 3$)$. On the other side, the proportion of women with impaired glucose tolerance was lower among women who lactated for a total $\geq 10$ months $(P=0.001$, Table 3). Compared with women who lactated for a total $<10$ months, women who lactated for a total $\geq 10$ months had significantly lower fasting and $2-\mathrm{h}$ post-OGTT insulin concentrations as well as lower AUC for insulin ( $P \leq 0.01$ for all, Table 3$)$. These women also had higher HOMA-IS and Matsuda indices $(P \leq 0.01$ for both, Table 3$)$. There was no difference in insulin secretion indices $(P>0.05$, Table 3$)$ but we observed better insulin secretion at a comparable level of insulin sensitivity (ISSI) $(P=0.03$, Table 3$)$. Results were similar after adjustments for age, current energy intake, current physical activity, current BMI, insulin use during pregnancy, education level, parity, and time since last GDM-complicated pregnancy delivery. Analyses without women with T2D showed similar results (data not shown).

Having shown that insulin concentration, sensitivity, and secretion as well as glucose tolerance vary according to lactation categories, multiple linear regression analyses were performed. They were used to determine whether lactation duration, as a continuous variable, remained an independent predictor of 
Table 2 Association between lactation and insulin and glucose response $(n=144)$. Results are presented as mean \pm S.D. for continuous variables and as $n(\%)$ for categorical variables.

\begin{tabular}{|c|c|c|c|}
\hline Variables & Lactation $(n=116)$ & No lactation $(n=28)$ & $\boldsymbol{P}^{*}$ \\
\hline Age (years) & $36.9 \pm 4.9$ & $34.8 \pm 5.2$ & 0.04 \\
\hline Parity & $2.1 \pm 0.8$ & $1.8 \pm 0.8$ & 0.08 \\
\hline Energy intake (kcal) & $2328 \pm 669$ & $2061 \pm 491$ & 0.06 \\
\hline Physical activity (min/week) & $105 \pm 158$ & $78 \pm \overline{115}$ & 0.39 \\
\hline Insulin use & & & 0.26 \\
\hline Yes & $61(85.9)$ & $10(14.1)$ & \\
\hline No & $55(75.3)$ & $18(24.7)$ & \\
\hline $\begin{array}{l}\text { Time since last GDM-complicated } \\
\text { pregnancy delivery (years) }\end{array}$ & $4.1 \pm 1.9$ (range: $1-7)$ & $3.5 \pm 1.8$ (range: $1-7$ ) & 0.12 \\
\hline BMI $\left(\mathrm{kg} / \mathrm{m}^{2}\right)$ & $27.4 \pm 6.7$ & $27.8 \pm 5.9$ & 0.63 \\
\hline $\mathrm{BMl}$ at age $25\left(\mathrm{~kg} / \mathrm{m}^{2}\right)$ & $24.1 \pm 5.3$ & $24.5 \pm 5.1$ & 0.63 \\
\hline Education & & & 0.008 \\
\hline Secondary & $19(63.3)$ & $11(36.7)$ & \\
\hline Post secondary & $96(85.0)$ & $17(15.0)$ & \\
\hline Household income $(\$)$ & & & 0.26 \\
\hline 0-39 999 & $21(91.3)$ & $2(8.7)$ & \\
\hline $40000-79999$ & $37(77.1)$ & $11(22.9)$ & \\
\hline $80000+$ & $49(77.8)$ & $14(22.2)$ & \\
\hline Fasting glucose $(\mathrm{mmol} / \mathrm{l})$ & $5.8 \pm 0.7$ & $5.8 \pm 0.7$ & 0.99 \\
\hline 2-h post-OGTT glucose $(\mathrm{mmol} / \mathrm{l})$ & $8.4 \pm 2.2$ & $8.2 \pm 2.4$ & 0.64 \\
\hline Impaired fasting glucose & & & 0.88 \\
\hline Yes & $25(80.6)$ & $6(19.4)$ & \\
\hline No & $73(79.3)$ & $19(20.7)$ & \\
\hline Impaired glucose tolerance & & & 0.16 \\
\hline Yes & $31(79.5)$ & $8(20.5)$ & \\
\hline No & $67(79.8)$ & $17(20.2)$ & \\
\hline Fasting insulin (pmol/l) & $82.3 \pm 41.4$ & $107.6 \pm 58.9$ & 0.007 \\
\hline 2-h post-OGTT insulin (pmol/l) & $616 \pm 373$ & $844 \pm 586$ & 0.01 \\
\hline AUC for insulin (pmol// per min) & $60048 \pm 31340$ & $75420 \pm 36875$ & 0.01 \\
\hline HOMA-IS & $0.064 \pm 0.044$ & $0.045 \pm 0.021$ & 0.01 \\
\hline Matsuda & $10.9 \pm 5.9$ & $7.9 \pm 3.7$ & 0.007 \\
\hline Insulin secretion & $58.7 \pm 29.1$ & $70.3 \pm 31.3$ & 0.03 \\
\hline Insulinogenic index & $135 \pm 119$ & $142 \pm 84$ & 0.3 \\
\hline ISSI & $545 \pm 208$ & $494 \pm 179$ & 0.3 \\
\hline
\end{tabular}

${ }^{*} P$ values calculated by ANOVA for continuous variables and by $\chi^{2}$ test for categorical variables. OGTT, $75 \mathrm{~g}$ 2-h oral glucose tolerance test; AUC, area under the curve; HOMA-IS, homeostasis model assessment for insulin sensitivity; ISSI, insulin sensitivity-secretion index.

these characteristics. Lactation duration emerged as an independent predictor of insulin sensitivity indices (HOMA and Matsuda, $\beta=0.02, P=0.04$ for both) and fasting insulin concentrations $(\beta=-0.02, P=0.03)$ (Table 4) in a model including lactation duration in months, age, current energy intake, current physical activity, current BMI, insulin use during pregnancy, education level, parity, and time since last GDMcomplicated pregnancy delivery. In contrast, lactation duration was not an independent predictor of fasting and 2-h post-OGTT glucose concentrations, 2-h postOGTT insulin concentrations, AUC for insulin, and insulin secretion $(P>0.05$ for all, Table 4).

\section{Discussion}

Our objective was to investigate the impact of lactation on insulin and glucose response among women with prior GDM (mean 4 years after delivery). Results from our study showed that a large proportion of women with prior GDM breastfed their infant. Women who lactated had improved insulin sensitivity compared with women who did not lactate. Those with a total duration of lactation of at least 10 months were characterized by improved glucose tolerance as well as improved insulin sensitivity and insulin secretion for the degree of insulin sensitivity. We also showed that lactation duration was an independent predictor of fasting insulin concentrations and insulin sensitivity indices.

Results from the current study showed that $81 \%$ of women with prior GDM breastfed their children. Although a large proportion of women with prior GDM did breastfeed, this number is slightly lower than the data reported by the Canadian Community Health Survey (CCHS), which showed that $87.9 \%$ of women breastfed or tried to breastfeed their last child in 20072008 (23). This lower rate of breastfeeding among women with prior GDM is consistent with another study where data of breastfeeding habits of 257 mothers with GDM and 527 healthy mothers were recorded (24). Compared with healthy mothers, women with GDM breastfed less (75 vs $86 \%$ ) and for a shorter duration (median duration of any breastfeeding of 9 vs 17 
Table 3 Association between lactation duration and insulin and glucose response $(n=144)$. Results are presented as mean \pm s.D. for continuous variables and as $n(\%)$ for categorical variables.

\begin{tabular}{llll}
\hline Variables & $\begin{array}{l}\text { Lactation } \\
<\mathbf{1 0} \text { months }(n=70)\end{array}$ & $\begin{array}{l}\text { Lactation } \\
\geq \mathbf{1 0} \text { months }(n=74)\end{array}$ & $\boldsymbol{P}^{*}$ \\
\hline Age (years) & $36.2 \pm 5.3$ & $36.8 \pm 4.7$ & 0.50 \\
BMI (kg/m $\left.{ }^{2}\right)$ & $28.3 \pm 7.5$ & $26.6 \pm 5.3$ & 0.12 \\
Fasting glucose (mmol/l) & $5.8 \pm 0.6$ & $5.8 \pm 0.7$ & 0.68 \\
2-h post-OGTT glucose (mmol/l) & $8.5 \pm 2.2$ & $7.9 \pm 2.5$ & 0.11 \\
Impaired fasting glucose & & & 0.97 \\
Yes & $12(19.7)$ & $19(30.6)$ & \\
No & $49(80.3)$ & $43(69.4)$ & 0.001 \\
Impaired glucose tolerance & & & \\
Yes & $26(42.6)$ & $13(21.0)$ & 0.004 \\
No & $35(57.4)$ & $49(79.0)$ & 0.006 \\
Fasting insulin (pmol/l) & $97.7 \pm 51.5$ & $77.3 \pm 38.3$ & 0.009 \\
2-h post-OGTT insulin (pmol/l) & $766 \pm 500$ & $562 \pm 326$ & 0.01 \\
AUC for insulin (pmol// per min) & $70977 \pm 38082$ & $55613 \pm 25281$ & 0.002 \\
HOMA-IS & $0.050 \pm 0.026$ & $0.069 \pm 0.050$ & 0.09 \\
Matsuda & $9.0 \pm 4.6$ & $11.6 \pm 6.3$ & 0.49 \\
Insulin secretion & $65.4 \pm 31.9$ & $56.9 \pm 27.3$ & 0.03 \\
Insulinogenic index & $127 \pm 87$ & $145 \pm 132$ & \\
ISSI & $492 \pm 172$ & $576 \pm 222$ & \\
\hline
\end{tabular}

${ }^{\star} P$ values calculated by ANOVA for continuous variables and by $\chi^{2}$ test for categorical variables. OGTT, $75 \mathrm{~g} 2-\mathrm{h}$ oral glucose tolerance test; AUC, area under the curve; HOMA-IS, homeostasis model assessment for insulin sensitivity; ISSI, insulin sensitivity-secretion index.

weeks). Besides, we also saw in our study that the proportion of women who breastfeed increases with mother's age and education level, as in the CCHS study in Canada (23).

Our data suggest that women with prior GDM who lactated were characterized by improved insulin sensitivity. Lactation duration was also an independent predictor of insulin sensitivity. In contrast with results obtained in the current study, Diniz \& Da Costa (25) failed to find an association between lactation duration and insulin sensitivity at 12-18 months post partum in 67 women from the general population. In addition, an observational study of 26 women with prior GDM showed that insulin sensitivity was not significantly different between breastfeeding and non-breastfeeding women 3 months after a GDM-complicated pregnancy (10). In a larger study of women with prior GDM, the Study of Women, Infant Feeding, and Type 2 Diabetes (SWIFT), 522 participants were tested at 6-9 weeks after a GDM-complicated pregnancy (9). Exclusive breastfeeding or mostly breastfeeding women had lower HOMA-IR index but no differences were found with the mixed or inconsistent feeders compared with the formula feeding group (9). Whether the apparent benefit of lactation on insulin sensitivity persists after weaning is uncertain. Results from Project Viva showed that lactation was not associated with insulin resistance (assessed by HOMA-IR) among 175 women 3 years after delivery (26). However, results of this study suggest that lactation duration may have a beneficial effect with a mean of 4 years after delivery in women with prior GDM.

We also observed that lactation duration was associated with fasting and 2 -h post-OGTT insulin concentrations as well as insulin response. In a prospective study by Gunderson et al. (27), fasting insulin concentrations at 3-year follow-up increased more for women who did not lactate than for those who lactated and weaned $(n=109)$. Similarly, duration of lactation was inversely correlated with fasting insulin levels in a retrospective study including 2516 women (11). Diniz \& Da Costa (25) showed that lactation was inversely related to total insulin response (AUC for insulin) and to insulin peak (the highest concentration during an OGTT) (25). Whether these results reflect a sustained effect of lactation remained uncertain because $60 \%$ of participants were still breastfeeding (25). Results from Project Viva showed no association between lactation and fasting insulin in a multivariate model (26). In women with a pregnancy complicated with GDM from the SWIFT cohort, compared with exclusive or mostly formula feeding, women who were exclusively breastfeeding or mostly breastfeeding 6-9 weeks after delivery had lower fasting and 2-h post-OGTT insulin concentrations (9). These results combined with results from this study suggest that lactation is associated with lower insulin concentrations and reduced insulin response following a glucose challenge.

We did not observe association between lactation and glucose values or impaired fasting glucose or impaired glucose tolerance. However, lactation $\geq 10$ months was associated with a lower proportion of women with impaired glucose tolerance. In a study of 300 women with prior GDM and 220 controls, the prevalence of persistent hyperglycemia at 12 weeks post partum was lower in women who lactated vs women who did not lactate (6). Other studies have shown improved insulin homeostasis but no changes in glucose tolerance among 
Table 4 Multiple linear regression analyses of the relationships between lactation duration and insulin and glucose response $(n=144)$. Covariates included in the models but not significant: age, current energy intake, insulin use during pregnancy, parity, and time since last GDM-complicated pregnancy delivery.

\begin{tabular}{|c|c|c|c|}
\hline & $\beta$ & $\boldsymbol{P}$ & Model $r^{2}$ \\
\hline Fasting glucose $(\mathrm{mmol} / \mathrm{l})$ & & & 0.34 \\
\hline Lactation & -0.003 & 0.92 & - \\
\hline BMI & 3.13 & $<0.0001$ & - \\
\hline Physical activity & 0.0110 & 0.0003 & - \\
\hline Education level & 0.219 & 0.08 & - \\
\hline 2-h post-OGTT glucose $(\mathrm{mmol} / \mathrm{l})$ & & & 0.12 \\
\hline Lactation & 0.024 & 0.82 & - \\
\hline BMI & 7.95 & 0.0002 & - \\
\hline Physical activity & -0.0012 & 0.92 & - \\
\hline Education level & -0.234 & 0.64 & - \\
\hline Fasting insulin (pmol/l) & - & - & 0.39 \\
\hline Lactation & -0.018 & 0.03 & - \\
\hline BMI & 1.25 & $<0.0001$ & - \\
\hline Physical activity & -0.0015 & 0.11 & - \\
\hline Education level & 0.005 & 0.89 & - \\
\hline 2-h post-OGTT insulin (pmol/l) & - & - & 0.22 \\
\hline Lactation & -0.017 & 0.15 & - \\
\hline BMI & 1.04 & $<0.0001$ & - \\
\hline Physical activity & -0.0025 & 0.06 & - \\
\hline Education level & 0.038 & 0.49 & _- \\
\hline AUC for insulin (pmol/l per min) & - & - & 0.27 \\
\hline Lactation & -0.014 & 0.10 & - \\
\hline BMI & 0.91 & $<0.0001$ & - \\
\hline Physical activity & -0.0010 & 0.32 & - \\
\hline Education level & -0.013 & 0.74 & - \\
\hline HOMA-IS & - & - & 0.41 \\
\hline Lactation & 0.018 & 0.04 & - \\
\hline BMI & -1.48 & $<0.0001$ & - \\
\hline Physical activity & 0.0008 & 0.45 & - \\
\hline Education level & -0.020 & 0.62 & - \\
\hline Matsuda & - & - & 0.42 \\
\hline Lactation & 0.017 & 0.04 & - \\
\hline BMI & -1.35 & $<0.0001$ & - \\
\hline Physical activity & 0.0007 & 0.45 & - \\
\hline Education level & 0.004 & 0.91 & - \\
\hline Insulin secretion & - & - & 0.18 \\
\hline Lactation & -0.011 & 0.20 & - \\
\hline BMI & 0.58 & 0.0006 & - \\
\hline Physical activity & -0.0016 & 0.09 & - \\
\hline Education level & 0.011 & 0.77 & - \\
\hline Insulinogenic index & - & - & 0.11 \\
\hline Lactation & -0.004 & 0.76 & - \\
\hline BMI & 0.50 & 0.06 & - \\
\hline Physical activity & -0.0031 & 0.04 & - \\
\hline Education level & 0.133 & 0.03 & - \\
\hline ISSI & - & - & 0.24 \\
\hline Lactation & 0.006 & 0.35 & - \\
\hline BMI & -0.77 & $<0.0001$ & - \\
\hline Physical activity & -0.0009 & 0.26 & - \\
\hline Education level & 0.016 & 0.63 & - \\
\hline
\end{tabular}

OGTT, $75 \mathrm{~g}$ 2-h oral glucose tolerance test; AUC, area under the curve; HOMA-IS, homeostasis model assessment for insulin sensitivity; ISSI, insulin sensitivity-secretion index.

women who lactated, suggesting that lactation was associated with compensatory hyperinsulinemia but maintained normal glycemia $(25,28)$. Indeed, Tigas et al. (28) observed that lactating women handle oral carbohydrates normally but had increased insulin sensitivity.

It has been demonstrated that women with GDM have a chronic defect in $\beta$-cell function (29) and that there is a declining $\beta$-cell function in the first year following a pregnancy affected by GDM (17). To our knowledge, only one study investigated the relationship between lactation and $\beta$-cell function in women with prior GDM. A significantly higher $\beta$-cell function was observed in 14 breastfeeding women compared with 12 non-breastfeeding women 3 months after a pregnancy complicated by GDM while there was no difference in 
either insulin sensitivity or insulin secretion (10). In this study, lactation per se was not associated with improved ISSI but we observed improved insulin secretion for the degree of insulin sensitivity (ISSI) among women who lactated $\geq 10$ months. However, in a multiple regression model, lactation duration was no longer significant when other variables were included in the model, suggesting that other studies are needed to understand the impact of lactation and lactation duration on insulin secretion.

Other studies have looked at long-term impact of lactation duration on subsequent risk of metabolic disease in women with GDM. Among 84 women with prior GDM, increased duration of lactation was associated with a lower incidence of the metabolic syndrome during a 20-year period in the Coronary Artery Risk Development in Young Adults Study (30). In the Nurses' Health Study, increasing duration of lactation was associated with a reduced risk of T2D in the group never diagnosed with GDM but had no effect on T2D risk in the GDM group (31).

Some mechanisms underlying a possible preventive role of lactation for maternal insulin metabolism have been proposed. The effect of lactation on insulin secretion could be mediated by direct prolactin action as levels increase with lactation (32). Prolactin has been shown to stimulate insulin secretion (32) through stimulation of $\beta$-cell proliferation by downregulating the expression of menin (33). Prolactin levels remain high during lactation, suggesting that the hormone may play a role in regulating insulin secretion and glucose homeostasis in the post partum period (34). Unfortunately, we were unable to obtain data on changes in the hormonal milieu during and after pregnancy that would have allowed us to explore underlying metabolism and confirm that the hormonal changes were induced by lactation. Another proposed mechanism is that glucose could be preferentially diverted for lactogenesis via a non-insulin-mediated pathway of uptake by the mammary gland, which may unload the pancreatic $\beta$-cells and preserve long-term insulin production in women (35). Lactation can have a prolonged effect through an effect on adipose tissue metabolism by mobilizing lipids accumulated in liver and muscle into breast milk instead of redirecting lipid to adipocytes that are already enlarged (36). Also, prolactin modulates the transcription factors STAT5 and PPAR $\gamma$, and the expression of lipoprotein lipase, which are co-expressed in breast, adipose tissue, and skeletal muscle (36). A non-lactating woman would be at higher risk of storing lipids in non-adipose tissues resulting in further compromise of the balance between insulin secretion and insulin sensitivity (36). Further research is needed to explain the mechanism involved in the association between lactation and insulin and glucose response and especially regarding the longterm effect of lactation.
Limitations of the current study include the possibility that some confounding factors were not taken into consideration. Indeed, a healthier lifestyle among women who lactated is possible and could explain part of the long-term association between lactation and insulin homeostasis. However, we were able to control for multiple potential confounders including current diet and physical activity in addition to current BMI, age, insulin use during at least one pregnancy, education level, parity, and time since last GDMcomplicated pregnancy delivery. Lactation duration was obtained from an open question but may have been subject to recall bias as breastfeeding was selfreported retrospectively $\sim 4$ years after delivery. However, maternal recall does provide accurate estimates of initiation and duration of breastfeeding with high validity according to a review of 11 studies (37). Furthermore, data on the metabolic profile before pregnancy or in the early post partum period were not available in this study. Several conditions have been shown to impact initiation of breastfeeding including maternal obesity, a condition often associated with GDM. Although BMI in the early post partum period was not available, we did have BMI prior to any pregnancy and it was not different between the lactation groups. Finally, because of the design of the study, we cannot conclude that there is a causal link between lactation duration and the insulin profile.

In conclusion, our data provide evidence that lactation may have favorable effects on insulin and glucose response up to a mean of 4 years after delivery among women with a history of GDM who are more susceptible to develop T2D. The effects seemed to be greater with increasing duration of lactation $(>10$ months). Our study supports a growing body of evidence showing that lactation may have benefits on maternal insulin and glucose metabolism years after weaning and that lifestyle behaviors do not explain the associations. Encouraging women to breastfeed and to persist in breastfeeding may provide an important strategy for reducing the T2D risk in women with prior GDM. Further investigations and prospective studies are needed to elucidate the mechanisms through which lactation may influence metabolic risk profiles, and whether lifestyle modification, including lactation duration, may affect development of diseases, particularly among high-risk groups such as women with a history of GDM.

\section{Declaration of interest}

The authors declare that there is no conflict of interest that could be perceived as prejudicing the impartiality of the research reported.

\section{Funding}

A Tchernof is the recipient of a senior scholarship from the Fonds de la recherche en santé du Québec (FRSQ). J Robitaille is the recipient of a Junior Investigator scholarship from the FRSQ. The study was 
supported by a grant from the FRSQ and the Canadian Institutes of Health Research (CIHR) (OOP \#98026).

\section{Author contribution statement}

S Chouinard-Castonguay reviewed the literature, participated in recruitment of subjects, collected data, performed the statistical analyses, interpreted the data, and wrote the manuscript; S J Weisnagel and A Tchernof assisted with the development of the research study design and protocol as well as data analysis and interpretation; J Robitaille was the principal investigator and designed the study, supervised the research, directed the data analysis and interpretation, and assisted with the manuscript preparation. All the authors revised the manuscript.

\section{Acknowledgements}

The authors thank all the participants of this study. They would also like to express their gratitude to Geneviève Faucher, MSc, RD, for her assistance and technical support throughout the study.

\section{References}

1 Standards of medical care in diabetes - 2007. Diabetes Care 2007 30 (Suppl 1) S4-S41.

2 Xiang AH, Peters RK, Trigo E, Kjos SL, Lee WP \& Buchanan TA. Multiple metabolic defects during late pregnancy in women at high risk for type 2 diabetes. Diabetes $1999 \mathbf{4 8} 848-854$. (doi:10.2337/diabetes.48.4.848)

3 Lim S, Choi SH, Park YJ, Park KS, Lee HK, Jang HC, Cho NH \& Metzger BE. Visceral fatness and insulin sensitivity in women with a previous history of gestational diabetes mellitus. Diabetes Care 200730 348-353. (doi:10.2337/dc06-1405)

4 Corrado F, D’Anna R, Cannata ML, Cannizzaro D, Caputo F, Raffone E \& Di Benedetto A. Positive association between a single abnormal glucose tolerance test value in pregnancy and subsequent abnormal glucose tolerance. American Journal of Obstetrics and Gynecology $2007 \quad 196$ 339.e1-339.e5. (doi:10.1016/j.ajog.2006.11.016)

5 Albareda M, Caballero A, Badell G, Piquer S, Ortiz A, de Leiva A \& Corcoy R. Diabetes and abnormal glucose tolerance in women with previous gestational diabetes. Diabetes Care 200326 1199-1205. (doi:10.2337/diacare.26.4.1199)

6 O'Reilly MW, Avalos G, Dennedy MC, O'Sullivan EP \& Dunne F. Atlantic DIP: high prevalence of abnormal glucose tolerance post partum is reduced by breast-feeding in women with prior gestational diabetes mellitus. European Journal of Endocrinology 2011165 953-959. (doi:10.1530/EJE-11-0663)

7 Schwarz EB, Ray RM, Stuebe AM, Allison MA, Ness RB, Freiberg MS \& Cauley JA. Duration of lactation and risk factors for maternal cardiovascular disease. Obstetrics and Gynecology 2009113 974-982.

8 Ziegler AG, Wallner M, Kaiser I, Rossbauer M, Harsunen MH, Lachmann L, Maier J, Winkler C \& Hummel S. Long-term protective effect of lactation on the development of type 2 diabetes in women with recent gestational diabetes mellitus. Diabetes 2012 61 3167-3171. (doi:10.2337/db12-0393)

9 Gunderson EP, Hedderson MM, Chiang V, Crites Y, Walton D, Azevedo RA, Fox G, Elmasian C, Young S, Salvador N et al. Lactation intensity and postpartum maternal glucose tolerance and insulin resistance in women with recent GDM: the SWIFT cohort. Diabetes Care 201235 50-56. (doi:10.2337/dc11-1409)

10 McManus RM, Cunningham I, Watson A, Harker L \& Finegood DT. $\beta$-Cell function and visceral fat in lactating women with a history of gestational diabetes. Metabolism 200150 715-719. (doi:10.1053/meta.2001.23304)

11 Ram KT, Bobby P, Hailpern SM, Lo JC, Schocken M, Skurnick J \& Santoro N. Duration of lactation is associated with lower prevalence of the metabolic syndrome in midlife - SWAN, the study of women's health across the nation. American Journal of Obstetrics and Gynecology $2008 \mathbf{1 9 8}$ 268.e1-268.e6. (doi:10.1016/j.ajog.2007.11.044)

12 Gingras V, Paradis A, Tchernof A, Weisnagel S \& Robitaille J. Relationship between the adoption of preventive practices and the metabolic profile of women with prior gestational diabetes mellitus. Applied Physiology, Nutrition, and Metabolism 201237 1232-1238. (doi:10.1139/h2012-114)

13 Richterich R \& Dauwalder H. Determination of plasma glucose by hexokinase-glucose-6-phosphate dehydrogenase method. Schweizerische Medizinische Wochenschrift 1971101 615-618.

14 Desbuquois B \& Aurbach GD. Use of polyethylene glycol to separate free and antibody-bound peptide hormones in radioimmunoassays. Journal of Clinical Endocrinology and Metabolism 197133 732-738. (doi:10.1210/jcem-33-5-732)

15 Matthews DR, Hosker JP, Rudenski AS, Naylor BA, Treacher DF \& Turner RC. Homeostasis model assessment: insulin resistance and $\beta$-cell function from fasting plasma glucose and insulin concentrations in man. Diabetologia 198528 412-419. (doi:10.1007/ BF00280883)

16 Matsuda M \& DeFronzo RA. Insulin sensitivity indices obtained from oral glucose tolerance testing: comparison with the euglycemic insulin clamp. Diabetes Care 199922 1462-1470. (doi:10.2337/diacare.22.9.1462)

17 Retnakaran R, Qi Y, Sermer M, Connelly PW, Hanley AJ \& Zinman B. $\beta$-Cell function declines within the first year postpartum in women with recent glucose intolerance in pregnancy. Diabetes Care 201033 1798-1804. (doi:10.2337/dc10-0351)

18 Retnakaran R, Shen S, Hanley AJ, Vuksan V, Hamilton JK \& Zinman B. Hyperbolic relationship between insulin secretion and sensitivity on oral glucose tolerance test. Obesity $2008 \mathbf{1 6}$ 1901-1907. (doi:10.1038/oby.2008.307)

19 Retnakaran R, Qi Y, Goran MI \& Hamilton JK. Evaluation of proposed oral disposition index measures in relation to the actual disposition index. Diabetic Medicine 200926 1198-1203. (doi:10.1111/j.1464-5491.2009.02841.x)

20 Seltzer HS, Allen EW, Herron AL Jr \& Brennan MT. Insulin secretion in response to glycemic stimulus: relation of delayed initial release to carbohydrate intolerance in mild diabetes mellitus. Journal of Clinical Investigation $1967 \mathbf{4 6}$ 323-335. (doi:10.1172/JCI105534)

21 Goulet J, Nadeau G, Lapointe A, Lamarche B \& Lemieux S. Validity and reproducibility of an interviewer-administered food frequency questionnaire for healthy French-Canadian men and women. Nutrition Journal 20043 13. (doi:10.1186/14752891-3-13)

22 Craig CL, Marshall AL, Sjostrom M, Bauman AE, Booth ML, Ainsworth BE, Pratt M, Ekelund U, Yngve A, Sallis JF et al. International physical activity questionnaire: 12-country reliability and validity. Medicine and Science in Sports and Exercise 2003 35 1381-1395. (doi:10.1249/01.MSS.0000078924.61453.FB)

23 Canada S. Choix de l'allaitement au Canada: statistiques et graphiques clés (2007-2008). 2007-2008.

24 Hummel S, Hummel M, Knopff A, Bonifacio E \& Ziegler AG. Breastfeeding in women with gestational diabetes. Deutsche Medizinische Wochenschrift 2008133 180-184. (doi:10.1055/ s-2008-1017493)

25 Diniz JM \& Da Costa TH. Independent of body adiposity, breastfeeding has a protective effect on glucose metabolism in young adult women. British Journal of Nutrition 200492 905-912. (doi:10.1079/BJN20041288)

26 Stuebe AM, Kleinman K, Gillman MW, Rifas-Shiman SL, Gunderson EP \& Rich-Edwards J. Duration of lactation and maternal metabolism at 3 years postpartum. Journal of Women's Health 201019 941-950. (doi:10.1089/jwh.2009.1660)

27 Gunderson EP, Lewis CE, Wei GS, Whitmer RA, Quesenberry CP \& Sidney S. Lactation and changes in maternal metabolic risk factors. Obstetrics and Gynecology 2007109 729-738. (doi:10.1097/ 01.AOG.0000252831.06695.03) 
28 Tigas S, Sunehag A \& Haymond MW. Metabolic adaptation to feeding and fasting during lactation in humans. Journal of Clinical Endocrinology and Metabolism 200287 302-307. (doi:10.1210/ jc.87.1.302)

29 Buchanan TA \& Xiang AH. Gestational diabetes mellitus. Journal of Clinical Investigation 2005115 485-491. (doi:10.1172/JCI24531)

30 Gunderson EP, Jacobs DR Jr, Chiang V, Lewis CE, Feng J, Quesenberry CP Jr \& Sidney S. Duration of lactation and incidence of the metabolic syndrome in women of reproductive age according to gestational diabetes mellitus status: a 20-Year prospective study in CARDIA (Coronary Artery Risk Development in Young Adults). Diabetes 201059 495-504. (doi:10.2337/db09-1197)

31 Stuebe AM, Rich-Edwards JW, Willett WC, Manson JE \& Michels KB. Duration of lactation and incidence of type 2 diabetes. Journal of the American Medical Association $20052942601-2610$. (doi:10.1001/jama.294.20.2601)

32 Crepaldi SC, Carneiro EM \& Boschero AC. Long-term effect of prolactin treatment on glucose-induced insulin secretion in cultured neonatal rat islets. Hormone and Metabolic Research 199729 220-224. (doi:10.1055/s-2007-979025)

33 Karnik SK, Chen H, McLean GW, Heit JJ, Gu X, Zhang AY, Fontaine M, Yen MH \& Kim SK. Menin controls growth of pancreatic $\beta$-cells in pregnant mice and promotes gestational diabetes mellitus. Science $2007 \mathbf{3 1 8} 806-809$. (doi:10.1126/ science.1146812)

34 Stuebe AM \& Rich-Edwards JW. The reset hypothesis: lactation and maternal metabolism. American Journal of Perinatology 2009 26 81-88. (doi:10.1055/s-0028-1103034)

35 Butte NF, Hopkinson JM, Mehta N, Moon JK \& Smith EO. Adjustments in energy expenditure and substrate utilization during late pregnancy and lactation. American Journal of Clinical Nutrition 199969 299-307.

36 Ramos-Roman MA. Prolactin and lactation as modifiers of diabetes risk in gestational diabetes. Hormone and Metabolic Research 201143 593-600. (doi:10.1055/s-0031-1284353)

37 Li R, Scanlon KS \& Serdula MK. The validity and reliability of maternal recall of breastfeeding practice. Nutrition Reviews 2005 63 103-110. (doi:10.1111/j.1753-4887.2005.tb00128.x)

Received 26 October 2012

Revised version received 27 December 2012

Accepted 8 January 2013 